\title{
Substantivismo econômico e história florestal da América portuguesa*
}

\section{Portuguese America's economic substantivism and forest history}

\author{
DIOGO DE CARVALHO CABRAL \\ Mestre em História Social (PPGHIS/UFRJ) \\ Geógrafo (IGEO/UFRJ) \\ J ardim Botânico do Rio de J aneiro, Rua J ardim Botânico, 1008, Espaço Tom J obim, J d. Botânico, Rio \\ de J aneiro - RJ , CEP 22460-000 \\ diogocabral@superig.com.br
}

RESUMO Embora alguns importantes escritos anteriores já atentassem para a importância do tema e, de certa forma, prenunciassem um delineamento do objeto, pode-se dizer que With Broadax and Firebrand, de Warren Dean (1995) e Fruitless Trees, de Shawn Miller (2000), são, de fato, as obras fundadoras da historiografia florestal da América portuguesa. Dean e Miller estabeleceram os parâmetros gerais para o estudo da Mata Atlântica colonial sob o ponto de vista dos processos político-econômicos de apropriação e uso dos recursos ambientais, tanto no que concerne às formas de abordagem como no que concerne às hipóteses explicativas. Não obstante, esses dois trabalhos não incorporam a poderosa tendência,

Artigo recebido em: 14/08/2007. Aprovado em: 06/10/2007. 
verificada na última década, de uma abordagem da economia colonial fortemente influenciada por autores como Marcel Mauss, Karl Polanyi e Giovanni Levi, gerando toda uma revisão acerca dos determinantes da economia luso-brasileira. 0 presente artigo pretende-se uma crítica da historiografia florestal tal como delineada por Dean e Miller a partir dessa postura econômico-substantivista.

Palavras-chave Historiografia florestal, substantivismo econômico, América portuguesa

ABSTRACT Although some important precedent works already called attention to the theme and, in a certain way, foretold a delineation of the object, it may be said that Warren Dean's With Broadax and Firebrand (1995) and Shawn Miller's Fruitless Trees (2000) are the real founders of Portuguese America's foresthistoriography. Dean and Miller have established the general parameters for the study of colonial Atlantic Forest from the point of view of politic-economical processes of appropriation and use of environmental resources, both concerning the forms of approach and the explicative hypotheses. Notwithstanding, these two works do not incorporate the powerful trend, observed in the last decade, of a colonial economy's approach strongly influenced by author such as Marcel Mauss, Karl Polanyi e Giovanni Levi, generating a great revision on the determinants of Luso-Brazilian economy. This article aims itself a critic of forest historiog raphy such as sketched out by Dean and Miller from the prism of this economic-substantivist attitude.

Key-words Forest historiography, Economic substantivism, Portuguese America

A despeito do amplo sucesso contemporâneo da abordagem ambiental nas ciências humanas e sociais em geral, ela não vem obtendo muita - para não dizer nenhuma - receptividade entre os historiadores econômicos. É possível que isto esteja associado a uma interpretação como a de Peter Burke, para quem a emergência da história ambiental representa uma ameaça à "verdadeira" identidade da história econômica. ${ }^{1} \mathrm{O}$ autor destas linhas prefere endossar a posição de J oan Martínez Alier, para quem o que há - ou, pelo menos, o que deve haver - é uma recolocação dos problemas ou talvez mesmo uma ampliação do escopo de investigação propiciada

1 BURKE, Peter. Abertura: a nova história, seu passado e futuro. In: A escrita da história: novas perspectivas. São Paulo: Unesp, 1992, p.8. 
pela aplicação de uma abordagem ecológica aos temas tradicionais da história econômica. ${ }^{2}$

Além disso, devemos lembrar que este suposto "roubo" de objeto - se é que podemos colocar dessa forma - é propiciado pela própria dinâmica epistemológica interna à história econômica. Por um lado, e a despeito de certo revigoramento observado nos últimos anos, ${ }^{3}$ é ponto pacífico que a prática da histórica econômica foi relativamente abandonada entre os anos 1970 e 90 . Por outro lado, grande parte do interesse dos historiadores econômicos remanescentes deslocou-se da esfera da produção para a da circulação/distribuição e do consumo ${ }^{4}$ deixando em aberto um nicho que alguns historiadores ambientais não têm hesitado em ocupar, principalmente quando se trata daqueles setores mais a montante da cadeia produtiva, isto é, mais diretamente dependentes dos recursos naturais, renováveis ou não. ${ }^{5}$ É no âmbito da produção, do trabalho, que as relações com 0 mundo natural são mais evidentes. Neste sentido, não se pode negar que foi perdida uma antiga orientação da história econômica, a qual ainda pode ser encontrada, por exemplo, num trabalho clássico como o de Witold Kula; para este historiador, a existência humana depende, inevitavelmente, da transformação das substâncias naturais. ${ }^{6}$

Muito lentamente, esta perspectiva vem sendo recuperada por autores como Vera Lúcia Muniz, para quem a ênfase sobre os recursos naturais constitui-se na referência fundamental para a delimitação do meio ambiente como objeto da história econômica. ${ }^{7}$ Marcos L. Martins (outro historiador econômico por formação), em seu recém-publicado História e Meio Ambiente, acentua a necessidade do diálogo com a história ambiental, dado que ambas as subdisciplinas encontram suas razões de ser no desvelamento das condições materiais de reprodução das sociedades. Tratar-se-ia, sobretudo, da incorporação de variáveis ecológicas (clima, solo, hidrografia, etc.), não mais como

2 ALIER, J oan Martínez. De la economia ecológica al ecologismo popular. Montevidéu: Editorial Nordan-Comunidad, 1995, p.165-195.

3 Um espaço de cinco anos foi suficiente para FRAGOSO, J oão. Para que serve a história econômica? Notas sobre a exclusão social no Brasil. Estudos Históricos, v.29, p.3-38, 2002, suavizar seu ultra-pessimista diagnóstico sobre 0 estado da história econômica brasileira e internacional elaborado com FLORENTINO, Manolo. História econômica. In: CARDOSO, Ciro Flamarion; VAINFAS, Ronaldo. (ed.) Domínios da história: ensaios de teoria e metodologia. Rio de J aneiro: Campus, 1997, p.27-43.

4 Para uma breve consideração das causas desse deslocamento, ver LEVI, Giovanni. Comportamentos, recursos, processos: antes da 'revolução' do consumo. In: REVEL, Jacques. (ed.) Jogos de escalas: a experiência da microanálise. Rio de J aneiro: Ed. FGV, 1998, p.207-208.

5 Ver, e.g., TOTMAN, Conrad. The Lumber Industry in Early Modern J apan. Honolulu: University of Hawaii Press, 1995; SANTIAGO, Myrna. Rejecting Progress in Paradise: Huastecs, the Environment, and the Oil Industry in Veracruz, Mexico, 1900-1935. Environmental History, v.3, n.2, p.3-38, 1998; SLUYTER, Andrew. From Archive to Map to Pastoral Landscape: A Spatial Perspective on the Livestock Ecology of Sixteenth-Century New Spain. Environmental History, v.3, n.4, p.3-38, 1998; DRUMMOND, J osé Augusto. Environment, Society and Development: an Assessment of the Natural Resource Economy of the State of Amapá (Brazil). University of Wisconsin, 1999 (Tese de doutoramento); CABRAL, Diogo de Carvalho. Produtores rurais e indústria madeireira no Rio de J aneiro do final do século XVIII. Ambiente e Sociedade, v.7, n.2, p.125-143, jul./dez. 2004.

6 KULA, Witold. Problemas y métodos de la historia económica. Barcelona: Ediciones Península, 1977, p.528.

7 MUNIZ, Vera Lúcia T. História do meio ambiente como objeto da história econômica-sociocultural. Revista de Economia Política e História Econômica, n.3, p.51-74, junho 2005. 
"externalidades", mas como componentes de um quadro explicativo mais amplo e complexo - como, aliás, já foi feita por membros da Escola dos Annales, como Emmanuel Le Roy Ladurie - acerca das estruturas sócio-econômicas. ${ }^{8}$ $\mathrm{Na}$ formulação concisa e elegante de Enrique Leff, essa nova história "remete à emergência da complexidade ambiental que problematiza as relações entre ecologia e economia a partir do campo do poder e da cultura". ${ }^{9}$

Mas esse tipo de elucubração e sistematização teórica constitui uma preocupação deveras recente no Brasil, o que se apresenta como um relativo "atraso" no contexto mais amplo da América Latina. ${ }^{10}$ Somente de alguns poucos anos para cá é que os pesquisadores brasileiros tomaram para si a tarefa de criticar os esquemas e premissas da environmental history, buscando um sistema conceitual próprio, mais adequado à nossa realidade. ${ }^{11}$ Durante quase duas décadas, permanecemos firmemente atrelados às esquematizações norte-americanas, notadamente o modelo tripartite de Donald Worster, ${ }^{12}$ citado em to do e qualquer trabalho que se pretendesse, de alguma maneira, "histórico-ambiental".

Foi também através da escola norte-americana que, no âmbito da pesquisa empírica, "inaugurou-se" a história ambiental brasileira. Neste contexto, e a despeito de importantes estudos sobre temáticas variadas, ${ }^{13}$ certamente foram as florestas costeiras coloniais que constituíram o temachave ao redor do qual se formou um tópico de investigação de fôlego na historiografia brasileira (ou sobre o Brasil). Embora alguns importantes escritos anteriores já atentassem para a importância do tema e, de certa forma, prenunciassem um delineamento do objeto, ${ }^{14}$ pode-se dizer que $A$ Ferro e Fogo, de Warren Dean ${ }^{15}$ - cuja versão em português saiu da prensa há mais de 10 anos - e Fruitless Trees, de Shawn Miller ${ }^{16}$ - publicado em

8 MARTINS, Marcos Lobato. História e meio ambiente. São Paulo: Annablume, 2007, p.74-77.

9 LEFF, Enrique. Construindo a história ambiental da América Latina. Esboços, v.13, 2005, p.13.

10 A literatura histórico-ambiental hispânica de caráter senão propriamente "teórico-metodológico", mas pelo menos "esquemático", vem se adensando desde os anos 1980, vide GLIGO, Nicolo; MORELLO, J orgen. Notas sobre la Historia Ecológica de la América Latina. In: SÚNKEL, O; GLIGO, Nicolo. (eds.) Estilos de Desarrollo y Medio Ambiente em la América Latina. México: Fondo de cultura económica, 1980, p.129-57; VITALE, Luis. Hacia una Historia del Ambiente en América Latina. México: Nueva Sociedad/Editorial Nueva Imagen, 1983.

11 Como exemplos dessa empreitada, temos, além do já citado livro de Martins, DUARTE, Regina H. Por um pensamento ambiental histórico: o caso do Brasil. Luso-Brazilian Review, v.41, n.2, p.144-61, 2004; DUARTE, Regina H. História e natureza. Belo Horizonte: Autêntica, 2005; MARTINEZ, Paulo Henrique. História ambiental no Brasil: pesquisa e ensino. São Paulo: Cortez, 2006.

12 WORSTER, Donald. Para fazer história ambiental. Estudos Históricos, v.4, n.8, p.198-215, 1991.

13 DEAN, Warren. Indigenous Populations of the São Paulo-Rio de J aneiro Coast: Trade, Aldeamento, Slavery and Extinction. Revista de História, v.117, p.3-26, 1984; DEAN, Warren. Forest Conservation in Southeastern Brazil, 1900 to 1955. Environmental Review, v.9, n.1, p.55-69, 1985; DEAN, Warren. A botânica e a política imperial: a introdução e a domesticação de plantas no Brasil. Estudos Históricos, v.4, n.8, p.216-28, 1991; HEYNEMANN, Cláudia B. Floresta da Tijuca: natureza e civilização. Rio de J aneiro: Secretaria Municipal de Cultura do Rio de J aneiro, 1995.

14 MORTON, F.W.O. The Royal Timber in Late Colonial Bahia. Hispanic American Historical Review, v.58, p.41-61, 1978; DEAN, Warren. Ecological and Economic Relationships in Frontier History: São Paulo, Brazil. In: WOLFSKILL, George; PALMER, Stanley. (eds.) Essays on Frontiers in World History. College Station, TX: Texas A \& M University Press, 1983, p.71-100.

15 DEAN, Warren. A ferro e fogo: a história e a devastação da Mata Atântica brasileira. São Paulo: Cia. das Letras, 1996.

16 MILLER, Shawn W. Fruitless Trees: Portuguese conservation and Brazil's colonial timber. Stanford: Stanford University Press, 2000. 
inglês cinco anos depois, ainda sem tradução para o português -, são, de fato, as obras fundadoras desse campo que convenciono chamar de "história florestal da América portuguesa". Desde então (2000), muitos outros escritos, de autoria de historiadores brasileiros, vieram alentar essa área de pesquisa de maneira bastante significativa. ${ }^{17}$ Neste artigo, meus objetivos, contudo, não abarcam a análise desses trabalhos mais recentes, mas tãosomente as duas obras supracitadas; com efeito, Dean e Miller estabeleceram os parâmetros gerais para o estudo da Mata Atlântica colonial sob o ponto de vista dos processos político-econômicos de apropriação e uso dos recursos ambientais, tanto no que concerne às formas de abordagem como no que concerne às hipóteses explicativas.

Não obstante, esses dois trabalhos não incorporam a poderosa tendência, verificada na última década, de uma abordagem da economia colonial fortemente influenciada por autores como Marcel Mauss, Karl Polanyi e Giovanni Levi. Com efeito, esses aportes teóricos chamam a atenção para noções como reciprocidade e economia do dom, ensejando uma reinterpretação do Antigo Regime nos trópicos. ${ }^{18} \mathrm{Nesta}$ nova abordagem metodológica, tende-se a construir os objetos de estudo por meio de uma operação que poderíamos chamar de "(re)corte sociológico", isto é, procura-se abordar os grandes problemas que permeiam o sistema econômico - geografia, tecnologia, regulamentação administrativa, estrutura das empresas e modos de exploração, práticas comerciais - a partir dos atores e das redes de solidariedade social, muitas delas baseadas em relações que se situam "fora" da esfera econômica, como as parentais, políticas, etc. A intenção é captar o agenciamento econômico dos indivíduos dentro do quadro mais amplo das motivações culturais pertinentes a uma sociedade e a um tempo específicos, evitando modelos e categorias históricas "prontas" - como "capitalismo", "proletariado", "burguesia". ${ }^{19}$ Apresentar e discutir as formulações de Dean e Millera partir dessa vertente teórica econômico-substantivista será minha tarefa neste texto.

\section{I}

A idéia de que a colonização portuguesa criou, na América, um modelo econômico irresponsável, imprevidente e esbanjador é bastante antiga na historiografia e, de um modo geral, nas ciências sociais brasileiras. Embo-

17 Ver, por exemplo, CASTRO, Carlos F. de Abreu. Gestão florestal no Brasil Colônia. Brasília: Centro de Desenvolvimento Sustentável/UnB, 2002 (Tese de Doutorado); KIRSCHNER, Tereza Cristina. Entre o rei e a lei: natureza, legislação ilustrada e conflitos no final do período colonial. Textos de História, v.11, ns.1/2, p.47-62, 2003; CABRAL, Diogo de C. Produtores rurais e indústria madeireira no Rio de J aneiro do final do século XVIII; CABRAL. Madeireiros do Brasil colonial. Ciência Hoje, v.212, n.36, p.16-19, 2005; CABRAL, Diogo de C.; CESCO, Susana. A política da floresta: a instituição das 'madeiras-de-lei' na virada do século XVIII para o XIX. Anais eletrônicos do I Encontro Nordestino de História Colonial (CD-ROM). J oão Pessoa: Universidade Federal da Paraíba, 2006.

18 FRAGOSO. Para que serve a história econômica?, p.4-5.

19 GRIBAUDI, Maurizio. Escala, pertinência, configuração. In: REVEL, J ogos de escalas, p.123-128. 
ra a arqueologia intelectual dessa noção nos remeta a Sérgio Buarque de Holanda e Caio Prado J únior, ${ }^{20}$ ela somente foi de fato sistematizada como modelo explicativo na obra pioneira de Warren Dean. ${ }^{21}$

Embora A Ferro e Fogo não possa, em absoluto, ser considerada como uma obra de história econômica stricto sensu, seu autor, um antigo e experiente historiador da plantation cafeeira e da industrialização brasileira, ${ }^{22}$ tece profundas considerações sobre a economia política do processo de antropização da floresta atlântica. Dean desenvolve a idéia de que a taxa de conversão da floresta em capital (fixo e de giro) foi irrisória ao longo de todo o período de domínio português. Após o exame da situação da Mata Atlântica pós-mineração (um turning point na história da devastação desse bioma), atesta-se o seguinte:

É claro que a floresta não tinha sido transformada em capital, pelo menos não em capital localmente acumulado. Os escritórios governamentais, os fortes, as igrejas e conventos do Rio de J aneiro, a zona de mineração e uma única estrada não pavimentada que os conectava era tudo o que de substantivo se poderia considerar como o resultado destes cem anos de esforços que sacrificaram tantas vidas e tanta floresta. ${ }^{23}$

Mas, apesar do sentido de todos esses "esforços" ser o acúmulo de capital na metrópole - e não, naturalmente, na colônia -, nem mesmo este objetivo havia sido alcançado. A princípio, este fenômeno poderia ser explicado por causas externas, nomeadamente, as demandas do nascente capitalismo industrial britânico:

Um levantamento de um século de melhorias no estoque de capital social de Portugal talvez fornecesse justificativa para o desperdício de recursos que a Mata Atlântica sofrera, mas isso parece discutível. Será que uma proporção significativa da crescente riqueza britânica derivava de suas relações comerciais nitidamente assimétricas com Portugal, de seu financiamento do tráfico colonial de Portugal e de sua conseqüente extração de grande parte do ouro cobiçado? Se derivava, então (...) estava [-se] observando as conseqüências de uma relação (...) e a esterilidade da destruição da floresta pode ser atribuída, portanto, como muitos o fazem, ao colonialismo e ao capitalismo..$^{24}$

20 CABRAL, Diogo de C. Teorias da devastação ecológica colonial na historiografia brasileira contemporânea: algumas notas críticas. Anais eletrônicos do XXIV Simpósio Nacional de História (CD-ROM). São Leopoldo: ANPUH, 2007.

21 "Sérgio Buarque de Holanda, o maior historiador brasileiro deste século, escreveu (...) que os colonos queriam 'colher o fruto sem plantar a árvore'. 0 presente livro [A ferro e fogo] converte essa metáfora em história". SCWARTZ. Prefácio, p. 15. (grifo meu). Para uma crítica de A Ferro e Fogo de um ponto de vista da história sócio-cultural, ver CARVALHO, Ely Bergo de. Os historiadores e as florestas: dez anos depois de A Ferro e Fogo. Esboços, v.13, p.107-24, 2005.

22 Dean escreveu dois grandes clássicos da historiografia econômica brasileira: DEAN, Warren. A industrialização de São Paulo (1880-1945). São Paulo: Difel/Edusp, 1971; e DEAN, Warren. Rio Claro: um sistema brasileiro de grande lavoura, 1820-1920. Rio de J aneiro: Paz e Terra, 1977.

23 DEAN, Warren. A ferro e fogo, p.132.

24 DEAN, Warren. A ferro e fogo, p.132-3. 
Mas Dean não se contenta com a "conveniência dessa explicação e o apelo que ela faz a um sentimento universal pela justiça". Para ele, o que está em questão é "a efetividade e a eficiência com a qual se empregam recursos escassos, a habilidade que participa de sua transformação e a validade dos usos para os quais são empregados". Haveria, nesse sentido, fatores internos que não devem ser negligenciados:

(...) existem muitas evidências de que a autoridade real era obedecida apenas quando convinha aos colonos. As autoridades coloniais, na verdade, não raro se mostram mais esclarecidas e progressistas que seus governados em relação à exploração da natureza. Além disso, outros exemplos históricos demonstram que as colônias não estão necessariamente condenadas a níveis de formação de capital inferiores aos de suas metrópoles, e pode-se encarar a resistência às demandas do imperialismo como uma dinâmica histórica tão compulsória e determinante na formação de Estados e nações quanto o próprio imperialismo. ${ }^{25}$

Onde estaria, então, o primum mobile da ineficiência ecológica? Fica muito claro pela leitura dos capítulos 3, 4, 5 e 6 de A Ferro e Fogo (aqueles que cobrem diretamente o período colonial) - e a alusão aos "recursos escassos", um pressuposto fundamental da micro-economia neoclássica, apenas vem confirmar isso - que o problema da perdularidade advinha, na visão de Dean, de um defeito congênito do capitalismo luso-brasileiro: a imprevidência generalizada que esteve na base da formação da nossa cultura econômica, algo exatamente antipodal à frugalidade circunspeta tão cara à mentalité protestante, germe do genuíno espírito capitalista. No jogo de forças entre colônia e metrópole, prevaleciam os desígnios internos e o "o império se fundava solidamente nos desejos imediatos e predatórios dos colonos neo-europeus". ${ }^{26} \mathrm{~A}$ compreensão da formação sócio-ecológica colonial brasileira passa, então, obrigatoriamente, pelo

entendimento da construção de uma forma peculiar, extrativa, de capitalismo, na qual o estoque de capital é totalmente in natura, preexistente à ocupação neo-européia, e rapidamente dissipado. Ousaremos chamar isto de capitalismo, ou se trata de capitalismo pelo avesso? ${ }^{27}$

Ousaria reconhecer, aqui, uma verdadeira teoria psico-sociológica da perdularidade ecológica colonial. Embora não descarte os elementos estruturais - como a utilização do conceito de capitalismo comprova -, Dean claramente mostra-se um discípulo de Sérgio Buarque quando desenvolve sua narrativa da tragédia brasileira.

25 DEAN, Warren. A ferro e fogo, p.133.

26 DEAN, Warren. A ferro e fogo, p.99.

27 DEAN, Warren. A ferro e fogo, p.94. 
Contra o pano de fundo desse tema [a destruição da Floresta Atlântica], ele desenrola a história do Brasil, uma história crítica da exploração econômica, às vezes por necessidade, mas quase sempre pela ganância irrefreável com pouca ou nenhuma preocupação com a mata - símbolo, no Brasil, do atraso, do sub-desenvolvimento, do selvagem. ${ }^{28}$

Esta descrição de Schwart não poderia ser mais esclarecedora da essência teórico-metodológica da obra de Dean. 0 reino da "necessidade", isto é, o peso das demandas das estruturas político-econômicas sobre as decisões sociais é, em Dean, deveras diminuto. "A história, para Dean, era sempre ação humana e nunca determinada por estruturas ou contextos". ${ }^{29}$ Por isso, quase sempre era a "ganância irrefreável com pouco ou nenhuma preocupação com a mata" que explicava a atitude imprudente dos colonos frente aos recursos florestais. É a partir deste princípio que Dean constrói, de baixo para cima, seu conceito de "capitalismo extrativo".

Neste ponto, a pergunta que desejo fazer é a seguinte: de que modo a carga ideológica inevitavelmente acoplada ao uso do conceito de capitalismo pode enviesar a interpretação da realidade econômica e ecológica da colônia brasileira? É imprescindível pontuar que a mais recente epistemologia micro-analítica nos ensina a questionar as categorias apriorísticas, esses pacotes interpretativos monolíticos que necessitam apenas de dados empíricos corroborativos para lhes dara devida aparência de concretude. ${ }^{30}$ Nesse sentido, faz-se mister ter em mente que a conclusão de que a economia colonial foi ineficiente no aproveitamento dos recursos ambientais disponíveis foi construída de acordo com os parâmetros do que deveria ser o "ótimo" de uma economia capitalista - ou proto-capitalista. Mas e se incorporássemos os achados da nova história econômica colonial - achados estes que desenham o quadro de uma economia cuja reprodução estava longe de se encontrar auto-regulada, mas sim fortemente ancorada sobre relações de poder?

Seguindo a orientação substantivista da escola polanyiana, o que essa nova história mostra é que, para os agentes coevos, o agenciamento econômico era um meio, e não um fim em si mesmo; não havia uma esfera de motivação econômica individualizada. Considerando os efeitos da circularidade cultural, observamos que o chamado "ideal aristocratizante" permeava a ideologia de toda a sociedade colonial. A alta disseminação da propriedade de cativos pelo tecido social mostra como esse ideal alinhavase pari passu ao escravismo, enquanto a alta concentração dessa mesma propriedade nos aponta para uma sociedade na qual o principal objetivo da renda extraída ao escravo não é a reprodução ampliada do capital,

28 SCHWARTZ. Prefácio, p.15. (grifos meus).

29 SCHWARTZ. Prefácio, p.14.

30 GRIBAUDI. Escala, pertinência, configuração, p.123-128. 
mas a reiteração da diferença socioeconômica entre a elite escravocrata e todos os outros homens livres, isto é, a reiteração do mecanismo produtor do poder. ${ }^{31}$

O mais importante, aqui, contudo, é perceber as derivações desse fato no que tange ao grupo que controlava a reprodução da economia, isto é, os grandes comerciantes. Para estes, o desejo de afastar-se do mundo trabalho e, mais ainda, o desejo de controlar terras e homens conduzia a um investimento em status, e não em produção material. E é exatamente neste ponto que encontramos o maior empecilho à aplicação tout court do conceito de capitalismo à realidade colonial brasileira. Recorramos ao pensamento clarividente de Immanuel Wallerstein. Segundo ele, do ponto de vista histórico, a existência de capital (isto é, o estoque de bens consumíveis, maquinário, e/ou demandas reconhecidas de coisas materiais que se expressam sob a forma de dinheiro), por si só, não define um sistema social capitalista. É preciso que essa acumulação dos resultados do trabalho passado seja usada (investida) de maneira especial, tendo como intenção primordial a auto-expansão. "Nesse sistema, o que se acumulou no passado só é 'capital' na medida em que seja usado para acumular mais da mesma coisa". 32

Não era esse o caso dos agentes econômicos coloniais - pelo menos não majoritariamente - e também não surpreende, neste contexto, que a esterilização do excedente e a escravidão constituíssem traços estruturais dessa economia, traços esses que permitem redefinir a questão da perdularidade ecológica. Sabe-se que, por si mesma, uma economia marcada pela hegemonia do capital mercantil esteriliza enorme parcela do excedente produzido. ${ }^{33} \mathrm{E}$ o que, em termos ecológicos, significa a esterilização do excedente, senão um fluxo unilateral de matéria (elementos químicos) e energia para fora dos ecossistemas domesticados, um déficit permanente que impõe uma renovação dos estoques de nutrientes baseada num avanço sem-fim sobre novas terras e novas matas? "Na medida em que as energias gerais do país são destinadas à ampliação do poder do comerciante" - escrevia Henry Carey sobre os Estados Unidos, em 1858 -, "não é surpresa que 0 seu povo seja visto em toda parte como estando empregado em 'roubar a terra do seu estoque de capital'". ${ }^{34}$

Não obstante, isso não significa, em absoluto, que algum tipo de "riqueza social" não fosse produzida a partir da "riqueza florestal", no BrasilColônia. Quando menciona os "escritórios governamentais, os fortes, as

31 FRAGOSO, J oão; FLORENTINO, Manolo. O arcaísmo como projeto: mercado atlântico, sociedade agrária e elite mercantil em uma economia colonial tardia: Rio de J aneiro, c.1790-c.1840. 4ạ.ed. Rio de J aneiro: Civilização Brasileira, 2001, p.86-8, 123-5, 152-6.

32 WALLERSTEIN, Immanuel. Capitalismo histórico e civilização capitalista. Rio de J aneiro: Contraponto, 2001, p.13. (grifo meu)

33 FRAGOSO \& FLORENTINO. 0 arcaísmo como projeto, p.228.

34 Citado por FOSTER. A ecologia de Marx, p.216. 
igrejas e conventos do Rio de J aneiro, a zona de mineração e uma única estrada não pavimentada que os conectava" como as únicas expressões de conversão do capital in natura contido na floresta em capital social, Dean considera apenas o valor agregado ao solo (capital fixo) e esquece, imperdoavelmente, de contabilizar a principal forma de riqueza de giro encontrada na economia colonial: os escravos africanos. ${ }^{35}$ Embalado pela crítica apaixonada a um sistema de trabalho no qual "a conservação da vida humana era irrelevante", o historiador norte-americano inevitavelmente acaba por identificar a escravidão também a uma completa irrelevância atribuída à conservação dos recursos ambientais: ${ }^{36}$

É impossível calcular a extensão do impacto de um regime de trabalho agrícola escravo sobre a região de florestas do sudeste do Brasil; identificar esse impacto, porém, não é difícil. 0 afluxo desse grande contingente em si mesmo requeria áreas muito mais vastas para culturas de subsistência. Esses recrutas permitiram excluir os lavradores nativos itinerantes em regime de subsistência e os pequenos produtores de safras comerciais do comércio exportador, que os fazendeiros reservavam para si mesmos. Impossibilitavam, por outro lado, atrair para o Brasil um número significativo de trabalhadores imigrantes livres, o principal meio pelo qual o governo esperava transferir as práticas agrícolas mais intensivas da Europa para a atrasada colônia emancipada. 0 mais prejudicial eram as técnicas inevitáveis ao funcionamento das plantações escravistas. Constantemente movidos pela 'escassez de mão-de-obra', da qual a causa última era a expansão especulativa dos plantios e a recusa de uma força de trabalho escrava em trabalhar mais intensamente do que a chibata podia insuflar-lhes, os fazendeiros se envolveram em uma forma de agricultura tão exploradora que mal merece 0 nome de agricultura. Era inerentemente predatória: não podia ser intensificada e se expandia ao longo de uma fronteira de recursos até exauri-los. ${ }^{37}$

Mas o escravo, em si mesmo, não era uma riqueza? Se não o fosse, como poderia trabalhar para destruir algo? Independentemente da validade empírica de sua hipótese mais polêmica - a de que os negros africanos foram originalmente introduzidos, no Brasil, como meio de liquidação monetária -, é inevitável concordar com J orge Caldeira em sua afirmação de que os escravos eram, juntamente com a terra, os principais ativos da economia, ao mesmo tempo fonte de formação e aprisionamento de todas as fortunas rústicas. Como as opções de investimento, devido à falta crônica de numerário, eram restritíssimas, o destino do sobretrabalho escravo era sempre o de realimentar o sistema extensivo, requisitando e/ou ocupando mais terras, donde eram necessários mais cativos:

35 Vale lembrar que é somente a partir do último quartel do século XIX que a terra começa a substituir, de forma mais significativa, o escravo como equivalente de capital. Cf. MARTINS, J osé de Souza. 0 cativeiro da terra. 3a.ed. São Paulo: Hucitec, 1986, p.23-34.

36 DEAN, Warren. A ferro e fogo, p.75-76.

37 DEAN, Warren. A ferro e fogo, p.162. 
A importação maciça de africanos (...) do ponto de vista interno da Colônia implicava crescente agravamento das condições iniciais de falta de liquidez. Com a fortuna dos agentes aumentando em termos não-monetários (um patrimônio elevado mais dificilmente conversível em moeda, formado por engenhos e escravos, com apenas uma parte teoricamente conversível, o açúcar), e, mais ainda, aumentando em proporção maior que a moeda em circulação, seria inevitável o aumento das dificuldades para transformar a fortuna em dinheiro. Em outras palavras, (...) os brasileiros eram ricos, mas o dinheiro era uma miragem. ${ }^{38}$

Neste quadro, a posse de escravos - malgrado todos os riscos relativos à alta mortalidade negra - constituía-se num importante signo de reserva de valores. ${ }^{39}$ Argumentando nessa direção, Fernando Henrique Cardoso propôs um equivalente para a expressão típica de toda a documentação colonial e imperial brasileira, qual seja, a "deficiência de braços". "Esta 'deficiência de braços' era, realmente, uma deficiência de capitais", diz ele. Ter escravos, portanto, significava não somente ter trabalhadores à disposição; significava também ter capital, excedente acumulado ou, em outras palavras, "reinvestir, sob a forma de mão-de-obra escrava, o excedente gerado por seu trabalho". ${ }^{40}$ Ao baratear sobremaneira a mão-de-obra, 0 tráfico atlântico permitia a super-exploração do escravo, facilitando sua rápida substituição e diminuindo, assim, o intervalo entre o desembolso de recursos para a compra e o seu pagamento. Desse modo, as fases de expansão econômica elevam exponencialmente a velocidade de rotação do capital, compensando a lentidão da amortização da escravaria verificada nos períodos de retração do comércio externo. ${ }^{41}$

Ademais, conforme o próprio Dean comentou em passagem reproduzida acima, "as colônias não estão necessariamente condenadas a níveis de formação de capital inferiores aos de suas metrópoles". De fato, é o que a nova historiografia econômica tem mostrado para o caso brasileiro, principalmente a partir do século XVIII. O Brasil produzia muita riqueza e - o que é mais importante -, retinha uma parte bastante significativa dela. A principal forma na qual se consubstanciava essa grande quantidade de valor retido era exatamente a mercadoria humana. Para se ter uma idéia, no início do século XIX, quase 40 por cento da população brasileira era composta por escravos negros e mulatos, ${ }^{42}$ o que equivale a dizer, em última análise, que dois quintos do contingente demográfico colonial era composto de homens e mulheres que, em si mesmos, representavam repositários de valor mobilizável e reproduzível, tanto biológica quanto financeiramen-

38 CALDEIRA, J orge. A nação mercantilista. São Paulo: Ed. 34, 1999, p.67-68.

39 CALDEIRA, J orge. A nação mercantilista, p.72.

40 CARDOSO, Fernando Henrique. Capitalismo e escravidão no Brasil meridional. São Paulo: Difel, 1962, p.58-59.

41 GORENDER, J acob. O escravismo colonial. São Paulo: Ática, 1978, p.195, 197, 321-322.

42 MARCílIO, Maria Luiza. A população do Brasil colonial. In: BETHELL, Leslie. (org.) História da América Latina. Vol. 2: América Latina Colonial. São Paulo: Edusp/Funag, 1999, p.325. 
te. Sabe-se como era comum, no meio urbano, a prática de se comprar um escravo e "pactuar" uma série temporal de pagamentos contra a sua alforria, uma forma de geração de riqueza que constituía como que uma espécie de "proto-aplicação financeira". 0 crescimento da população servil é, desse modo, um excelente indicador da prosperidade de uma cidade num regime escravista. ${ }^{43}$ Sem embargo, para uma postura etnocêntrica, "verde", política e moralmente correta como a de Dean, assumir este fato seria completamente impensável.

Neste sentido, apesar de apresentar seu livro como a história de um "encontro [do homem] com o mundo natural", não creio que Dean tenha conseguido ultrapassar o tipo de historiografia que ele mesmo critica: "histórias de um breve momento na passagem das nações pela experiência da 'fronteira'". ${ }^{44}$ O Brasil, para Dean, resume-se, sim, a uma enorme "fronteira" conformada por uma mentalidade coletiva imprevidente e destruidora avançando sobre uma natureza idílica e vitimizada. Esse processo fronteiriço, no entanto, nada tem de "breve"; ele está ancorado sobre uma sociedade cuja verdadeira "estrutura de sentimento" é composta pelo desleixo, pela "visão de curto prazo", pela perdularidade irresponsável. Realmente, conforme lembrou Linda Lewin, Dean levou às últimas conseqüências a injunção bem-humorada de Capistrano de Abreu de que a história do Brasil podia ser reduzida a "papagaios, pau-brasil e escravos", embora eu me arrisque a apostar que este último dificilmente "aplaudiria de forma entusiástica" após a leitura de A Ferro e Fogo - de acordo com a especulação de Lewin. ${ }^{45}$

\section{II}

Pouco mais de dois anos depois da publicação de With Broadax and Firebrand (título original de A Ferro e Fogo), Shawn W. Miller defendia sua tese de doutoramento na universidade de Columbia. Considerando-se que Dean já vinha publicando seus resultados parciais de pesquisa, principalmente na Environmental Review (hoje Environmental History), pode-se vislumbrar a influência desses escritos na obra de Miller. Aceitando a premissa básica de Dean segundo a qual a história florestal brasileira - como, de resto, toda e qualquer história florestal "corretamente entendida" - foi uma história de destruição, Miller desloca, contudo, a discussão da esfera do "porque (e como) foi desmatado?" para a do "para quê foi desmatado?". Buscam-se as conseqüências econômicas do processo de desflorestamento. Neste

43 LESSA, Carlos. O Rio de todos os Brasis. Rio de J aneiro: Record, 2000, p.130-131.

44 DEAN, Warren. A ferro e fogo, p.22.

45 LEWIN, Linda. Review of 'With Broadaxand Firebrand: The Destruction of the Brazilian Atlantic Forest'. Luso-Brazilian Review, v.32, n.2, p.125, 1995. 
sentido, nada mais razoável do que investigar o aproveitamento primário de uma paisagem florestal em decomposição, qual seja, o da sua madeira.

Publicado como livro pela editora da universidade de Stanford, Fruitless Trees veio constituir um louvável primeiro esforço de desbravamento que logrou abrir o filão historiográfico da indús tria madeireira colonial no Brasil. ${ }^{46}$ Depois de pesquisar em arquivos e bibliotecas principalmente do Rio de J aneiro, Bahia, Paraíba e Pernambuco (além de escarafunchar, embora por um perío do curto, o Arquivo Histórico Ultramarino e o Arquivo Nacional da Torre do Tombo, em Lisboa), Miller burilou uma teoria que convenciono chamar de "entrave monopolístico estatal". Basicamente, ela estabelece uma relação de causalidade direta entre uma legislação florestal portuguesa altamente coercitiva e um desflorestamento que não se aproveitou do valorde-troca da biomassa não-carbonizada para a geração e acumulação de capital. Para Miller, o "conservacionismo" luso acabou por atuar no sentido contrário, isto é, incentivou os desmatamentos não-produtivos, na medida em que dificultou o aproveitamento comercial das madeiras pelos próprios fazendeiros, estimulando com isso a queima pura e simples das matas:

(...) colonial forest policy declared that Brazil's best trees, whether rooted on public or private land, held neither present nor future value for the colonists, for they were exclusive property of the king. Hence, the opportunity cost of slashing and burning the forest was almost nonexistent: one could expect no immediate returns while waiting for exhausted soils to recover, and there was no legal opportunity to turn the forest's trees to personal profit. Hence there are no examples of private conservation. One lost nothing and gained much by the destruction of the forest. The abundance of forested soils am timber's declared value of zero to the populace were the real incentives to cut it down and set it afire - of not just deforesting it, but destroying it. Due to the crown's unparalleled monopolization of timber resources, which it justified as conservation policy, timber trees remained obstacles to the pursuit of prosperity in Brazil, rather than serving as vehicles to that end, as they had in North America and elsewhere. ${ }^{47}$

Embora parta de uma orientação teórica diferente, S. W. Miller segue essencialmente a mesma linha ideológica de Dean, ${ }^{48}$ isto é, a crítica do colonialismo mercantilista e a apologia - aqui muito mais explícita - do capitalismo bem construído (leia-se "mercado auto-regulável"). 0 que muda em sua estratégia argumentativa é apenas a característica estatal responsável

46 Em sua revisão da obra, Stuart B. Schwartz considera muito judiciosamente que ela servirá, nos anos vindouros, como o ponto de partida fundamental para o estudo da indústria madeireira colonial brasileira. Ver SCHWARTZ, S. B. J oumal of Economic History, v.61, n.2, p.553.

47 MILLER. Fruitless Trees, p.9.

48 Como bem salientaram C. Brannstrom e Stefania Gallini, Dean e Miller encontram-se diametralmente opostos no espectro ecocentrismo-tecnocentrismo. Ver: BRANNSTROM, C. e GALINI, Stefania, DEAN e MILLER. An Introduction to Latin American Environmental History. In: BRANNSTROM, C. (ed.) Territories, Commodities and Knowledges: Latin American Environmental History in the Nineteenth and Twentieth Centuries. London: Institute for the Study of the Americas, 2004, p.9. 
pela "tragédia" da devastação das florestas costeiras - o que, de certo modo, muda o seu próprio sentido: se, para Dean, trata-se da espetacular e inaudita "imprevidência" e da "visão de curto prazo" da administração portuguesa - mas que acabava alastrando-se, como um câncer, para to do o corpo da sociedade civil -, para Miller, o problema está na profusão regulamentadora do governo colonial, expressa por procedimentos fiscalistas e, principalmente, monopolistas:

The destruction in Brazil was uncommon as a direct consequence of Portuguese Forest policy, which provided no incentives for conservation, few opportunities for timber profits, and every stimulus for landowners to destroy what, by decree, did not belong to them. Nearly all civilizations have destroyed their forests to some extent. What made Brazil peculiar was that she literally destroyed her trees. Deforestation is a tragedy; deforestation is an unmitigated disaster if little or no benefit is taken in the process. The Brazilian, for the most part, neither harvested nor exploited Brazil's high-quality timber trees, but annihilated them. And royal monopolization explains the colonist's motives for doing so. ${ }^{49}$

Para Miller, então, não importa o desalojamento da floresta per se, mas sim os benefícios econômicos que esse desflorestamento proporciona à sociedade que se engendra nesse avanço de fronteira. A devastação ambiental, de resto inevitável, deve oferecer uma contrapartida em termos de crescimento econômico, ao menos potencial. Neste processo, o Estado, ou melhor, a ausência dele, deve desempenhar um papel fundamental; cabe à livre-iniciativa, e somente a ela, regular o uso dos recursos, permitindo que se estabeleça um mercado competitivo para os produtos florestais e, conseqüentemente, a formação de capital a partir dessas transações. Obviamente que o modelo histórico subjacente, aqui, é o norte-americano, a partir do qual é feita a comparação com o caso brasileiro:

On the two-way street of humanity's relationship with the environment we have given close attention to human impact, but too little to the environment's rebounding influence. Painting broadly, the impact of westerns on the forests in North America and in Brazil exhibits little difference. But it is in the impact of the environment on the economy, the return relationship, that a real difference is noted. One economy took considerable benefit from the destruction. The other very little. ${ }^{50}$

A premissa neoclássica subjacente é a de que a privatização das florestas, trazendo consigo o direito de lucro futuro, provê o estímulo fundamental para que os madeireiros criem uma mentalidade econômica que associa a taxa atual de corte e o valor da madeira num cenário futuro. Em outras palavras: num mercado eficiente de produtos florestais, o preço

49 MILLER. Fruitless trees, p.8-9.

50 MILLER. Fruitless trees, p.9. 
reflete perfeitamente toda a informação necessária. ${ }^{51}$ De fato, estudos empíricos podem demonstrar a pertinência deste postulado em situações de paisagens florestais temperadas (leia-se biogeograficamente homogêneas), tecnologia de produção em massa, demanda madeireira diversificada e ampliada pelo desenvolvimento industrial e, principalmente, apropriação territorial diretamente taxada pelo Estado. ${ }^{52}$ Fica muito difícil defender a existência de qualquer um desses fatores no Brasil colonial.

De mais a mais, dizer que a maior economia colonial americana não tirou proveito da destruição florestal é, no mínimo, leviano. A maior falha de Miller é, no meu entender, não considerar, em momento algum, as diferenças marcantes na dinâmica de reprodução social existentes entre os Estados Unidos e o Brasil, diferenças essas que começam mesmo nas respectivas sociedades européias de cuja expansão essas sociedades advieram, bem como em seus projetos colonizadores. Parece-me que a questão não é, absolutamente, se a economia brasileira produziu capital internamente ou não, mas sim como esse capital era "aplicado" ou, em outras palavras, como a renda era alocada. Dependendo das motivações sociais e políticas dos agentes gerenciadores dos mecanismos de acumulação, uma floresta pode se transformar numa estrada ou num pelourinho, num moinho ou numa senzala - todas estas incontestes manifestações de riqueza, a única diferença sendo a matriz cultural a partir da qual elas são percebidas e valoradas. ${ }^{53} 0$ trecho a seguir, de autoria de Arthur Soffiati, é bem esclarecedor deste amplo espectro de possibilidades de destinações da renda extraída da conversão florestal:

\begin{abstract}
Não há dúvida de que a exploração florestal predatória foi uma das maiores fontes de recursos monetários do norte-noroeste fluminense. Recursos muito desigualmente distribuídos, diga-se passagem, e nem sempre retidos na ecorregião. (...). Os frutos da venda de lenha e de madeira (...) concentravam-se nas mãos dos médios e grandes proprietários rurais, que podiam investi-los na aquisição de mais terra, no crescimento da lavoura e da pecuária, na compra de engenhos e de alambiques ou na manutenção e modernização desta indústria. Podiam também sustentar modos de vida ostentatórios ou acabar nas mãos de comerciantes e agiotas. Por fim, podiam transferir-se para outras regiões dentro e fora do país. ${ }^{54}$
\end{abstract}

51 J OHNSON, Ronald N.; LIBECAP, Gary D. Efficient markets and Great Lakes timber: A conservation issue reexamined. Explorations in Economic History, v.17, p.383, 1980.

52 Na região estadunidense dos Grandes Lagos, o governo federal dirigiu a apropriação privada das terras florestadas, até pelo menos 1889, via venda de títulos fundiários. Cf. J OHNSON \& LIBECAP. Efficient markets and Great Lakes timber, p.374-377. Ver também, a esse respeito, ROBERTSON, Ross M. História da economia americana. Rio de J aneiro: Record, 1967, p.132-140.

53 “Às vezes esbanjou-se madeira de lei fazendo-se cercas enormes dividindo um engenho de outro. Luxo de privatismo. Vaidade de senhor de engenho patriarcal." FREYRE, Gilberto. Nordeste: aspectos da influência da cana sobre a vida e a paisagem do Nordeste do Brasil. 7ạ ed. São Paulo: Global, 2004, p.80.

54 SOFFIATI, Arthur. 0 nativo e 0 exótico: perspectivas para a história ambiental na ecorregião Norte-Noroeste fluminense entre os séculos XVII e XX. Rio de J aneiro: IFCS/UFRJ, 1996, p.161. (História Social, Dissertação de Mestrado). 
Esse cálculo econômico-ecológico da conversão florestal deve incorporar, portanto, um importante componente cultural. Mesmo que os processos de recursalização da floresta sejam conduzidos por agentes que operam dentro de uma racionalidade econômica instrumental, não devemos nos deixar seduzir pela forma, posto que seja o conteúdo, isto é, a motivação, que nos interessa. Isto implica "reconhecer diferentes formas de apropriação, ligadas a diferentes modos de vida e visões de mundo, de diferentes indivíduos e grupos, com diferentes formas de interação e diferentes identidades". ${ }^{55}$ Se a existência da floresta, enquanto entidade fisionômicopaisagística, materialidade geográfico-natural, não deve ser desvinculada dos significados que as diversas sociedades lhes conferem, por quê a sua transformação deveria? Enquanto ação ambiental, esse processo deve ser estudado de um ponto de vista substantivo, atento às lógicas cognitivas historicamente circunscritas dos atores que a peformatizam.

\section{III}

Essas duas breves análises abrem espaço para o apontamento de algumas diretrizes de pesquisa para desenvolvimento futuro. Sua apresentação mostra-se importante para o fortalecimento e a expansão desse campo de investigação histórica. Do ponto de vista de uma história econômica substantivista, essas diretrizes devem ser indicadas como temas relacionados aos atores sociais envolvidos, seus interesses, motivações e conflitos - todos eles devidamente situados historicamente.

Num primeiro nível de abordagem - de escala espacial e temporal mais grosseira -, a trama político-econômica que engendrava os processos de aprop riação das florestas costeiras brasileiras advinha, em grande medida, das ações do Estado colonial. Desde o pitoresco e emblemático momento em que os marinheiros da esquadra cabralina confeccionaram a tosca cruz de madeira sob a qual se ritualizou a pretensão de controle sobre o novo território, as políticas de Portugal em relação à Mata Atlântica brasileira foram, estruturalmente, na direção da conservação das espécies vegetais úteis ao aumento do poder naval imperial. Observando-se sinopticamente a história da legislação colonial, constata-se, todavia, conjunturas de "alta" e de "baixa", isto é, períodos de mais e menos intensidade na atividade legislativa, bem como no esforço de implementação e forcejamento desses sistemas reguladores. G rosso modo, podem ser identificad os três períodos de alta: entre o começo da ocupação efetiva do território, em 1532, quando as cartas de sesmarias já interditavam o acesso dos concessionários ao pau-brasil, até a incorporação da coroa portuguesa pela dinastia espanhola,

55 CARVALHO. Os historiadores e as florestas, p.116. 
em 1580; da restauração até o final do século XVII, período marcado por um esforço normativo numa etapa de consolidação do poder dos Bragança; ${ }^{56}$ e, finalmente, as últimas três décadas de domínio luso, quando, num contexto de decadência imperial e crise financeira pós-ciclo da mineração, tenta-se arrochar o pacto colonial, o que se expressa no plano florestal pela (tentativa de) monopolização régia de todas as matas à borda do mar e de todos os rios navegáveis (1797).

É importante salientar que, à exceção do pau-brasil, a exploração das madeiras da floresta brasileira não seguiu o processo tradicional da concessão de poderes e privilégios a empreendedores particulares em troca da assunção, por parte destes, dos riscos e investimentos iniciais - concessões essas que se iam restringindo à medida que aumentavam os índices de rentabilidade dos negócios. ${ }^{57}$ Desde o começo da colonização, a Coroa encarou a matéria como um assunto que tocava a manutenção da sua soberania, reservando para si a tarefa de gerenciar esse naipe de recursos. De fato, conforme aponta Richard G rove, as preocupações dos Estados coloniais de longo prazo em relação aos problemas de sup rimento de recursos naturais tendiam, na maioria das vezes, a entrar em desacordo com os interesses de curto prazo dos comerciantes e demais agentes capitalistas. ${ }^{58}$ Quase não há indícios de que empresas privadas tenham entrado no comércio externo de fibra lenhosa brasileira: a única que consegui identificar está no estudo de J orge Miguel Pedreira, que cita a casa de comércio anglo-suíça Purry $\&$ De Visme, a qual, segundo o autor, "costumava negociar em diamantes e madeiras do Brasil". ${ }^{59}$

Um tópico de investigação essencial, aqui, diz respeito à formulação das políticas econômicas de Portugal para a regulação das florestas costeiras brasileiras. Que tipo de concepções e teorias informavam essas políticas? Para respondermos esta pergunta, precisamos ir além da história do pensamento econômico luso - embora dele não se possa abrir mão; é necessário um escrutínio profundo do imaginário daquela sociedade a respeito do mundo natural, principalmente de seus setores dominantes. Como a tradição e o direito portugueses viam as florestas e seus produtos? Isto deve nos levar à evolução das doutrinas políticas absolutistas desde, pelo menos, o século XIII, bem como dos tratados geopolíticos. Outrossim, não se deve esquecer dos contextos objetivos que acompanhavam essas

56 MONTEIRO, Nuno G. F. A Consolidação da Dinastia de Bragança e o Apogeu do Portugal Barroco: centros de poder e trajetórias sociais. In: TENGARRINHA, J osé. (ed.) História de Portugal. São Paulo: Unesp, 2000, p.127-148.

57 SALGADO, Graça. (ed.) Fiscais e meirinhos: a administração no Brasil colonial. Rio de J aneiro: Arquivo Nacional, 1985, p.47.

58 GROVE, Richard H. Colonial conservation, ecological hegemony and popular resistance: towards a global synthesis. In: MACKENZIE, J. (ed.) Imperialism and the Natural World. Manchester: Manchester University Press, 1990, p.18.

59 PEDREIRA, J orge Miguel Viana. Os homens de negócio da praça de Lisboa de Pombal ao vintismo (1755-1822): diferenciação, reprodução e identificação de um grupo social. Lisboa: Faculdade de Ciências Sociais e Humanas, Universidade Nova de Lisboa, 1995, p.156. (História, Tese de Doutorado). 
formulações; a dinâmica de desflorestamento na península constitui uma história rica e cheia de descontinuidades.

Num nível de abordagem mais "fino", que traz ao palco histórico os agentes cujo raio de ação era geográfica, social e economicamente mais circunscrito - mas que nem por isso deixava de influenciar poderosamente as dinâmicas florestais, por efeito de sinergia -, encontramos a "burocracia florestal" (juízes conservadores das matas, arsenais de marinha, mestres de campo, administradores, etc.) e os grandes proprietários fundiários/ produtores rurais. É preciso ter sempre em mente que, na sua constante interação com o modelo de organização agrária aqui engendrado (largamente baseado no latifúndio), a legislação colonial portuguesa modelou, desde o começo, "um padrão especial de poder, onde o público e o privado se mesclaram de maneira a proporcionar os contornos da ordem jurídicoadministrativa implantada". ${ }^{60}$ Este amalgamento altamente irregular criou uma estrutura de direito florestal na qual, mais do que esferas estanques, bem delimitadas e organizadoras da prática cotidiana, o "público/estatal" e o "particular/privado" constituíam extremos raramente atingidos de um continuum conceitual que era manejado de acordo com as vicissitudes e peculiaridades de cada situação social concreta. Neste sentido, não se tratava, exatamente, de um solapamento - como queria Caio Prado ${ }^{61}$ - mas, sim, de uma negociação da autoridade pública, seguindo a noção proposta por J ack Greene. ${ }^{62}$

Quais eram as estratégias de que lançavam mão os potentados rurais contra uma burocracia florestal que procurava cercearseus direitos de exploração econômica em suas próprias terras? Para F. W. O. Morton, a maneira como ocorreu o fracasso das tentativas de "conservação florestal" no sul da Bahia, no final do século XVIII, pode ser muito valiosa para entendermos como funcionava a sociedade colonial tardia:

The crown, in the person of an exceptionally able and energetic minister [Souza Coutinho], who commanded the services of some of the best-educated Brazilians of the day, was unable to override the vested interests which had grown up in the timber and shipbuilding industries over the preceding century. This occurred even though the most powerful social group in the colony, the sugar magnates of the Recôncavo, saw no threat to their interests in the crown's plans for reform and (... ) remained aloof from the dispute throughout. The landowners and sawmill owners of Ilhéus and the merchants and shipbuilders of Salvador showed themselves fully capable of bringing enough pressure to bear on the local representatives of the crown to ensure abandonment, partly explicit, partly tacit, of the plano of 1799. The

60 SALGADO, Graça. Fiscais e meirinhos, p.48.

61 PRADO JÚNIOR, Caio. Formação do Brasil contemporâneo. 9a ed. São Paulo: Brasiliense, 1969, p.309.

62 GREENE, Jack P. Negotiated Authorities: Essays in colonial political and constitutional history. Charlottesville: University Press of Virginia, 1994, passim. 


\section{degree to which colonial B razil was governed and could only be governed in the interests of the local elites was strikingly confirmed. ${ }^{63}$}

O fato de que o "triunfo dos interesses locais" - uma expressão utilizada pelo próprio Morton para intitular a seção conclusória de seu artigo - tenha sido atingido sem a interferência daqueles agentes tradicionalmente reconhecidos pela historiografia como Os detentores do poder político (os senhores de engenho) é bastante instigante. As "elites locais" sobre as quais fala Morton são, com efeito, plurais, conformadas, entre outros fatores, pelas características técnicas e ecológicas desses agrupamentos sociais. Levando este raciocínio às últimas consequências, poder-se-ia mesmo conceber, nas regiões de produção madeireira mais pujante, a formação de uma elite que recrutasse seus membros naquela camada da população envolvida nessa economia - dentre outras, naturalmente. Ora, não é o que Guillermo Palacios encontrou em seu estudo sobre Pernambuco?

Os 'fabricantes das madeiras', como eram chamados, eram negociantes escravistas e exportadores que controlavam a economia alagoana pelo menos desde as décadas de 1720-1730, talvez com a mesma amplitude com que os grandes senhores de engenho e os comerciantes portugueses controlavam a pernambucana, mas com o agravante de estarem ligados a uma atividade vinculada ao equipamento bélico do Estado. Isso os tornava figuras de comunicação expedita e fluida com o centro do poder colonial, tanto no Recife como nos palácios da corte lisboeta. ${ }^{64}$

Essa assertiva traz sérias implicações, inclusive políticas - afinal de contas, pensar nos "madeireiros" coloniais como um grupo empresarial coeso e politicamente poderoso significa postular uma continuidade histórica de fazer revirar os olhos de qualquer ambientalista de hoje em dia. Contudo, antes que se comece a rever boa parte do que julgamos conhecer sobre a economia política colonial, precisamos de mais evidências de que os "fabricantes" e os "negociantes" eram os mesmos indivíduos ou, em outras palavras, se os capitais investidos na produção e comercialização vinham dos mesmos bolsos. Nesse sentido, seria de se desejar, de bom grado, um estudo prosopográfico sobre esse grupo social que era o dos comerciantes de madeira. Esse tipo de investigação, ao nos abrir as portas para o universo de sociabilidade desses indivíduos, poderia nos ajudar a responder perguntas-chave para a compreensão da história sócio-ambiental da indústria madeireira, tais como o papel dos comerciantes no estabelecimento do nível de oferta da madeira, o grau de especialização de suas

63 MORTON. The Royal Timber in Late Colonial Bahia, p. 60. (grifo meu).

64 PALACIOS, Guillermo. Campesinato e escravidão no Brasil: agricultores livres e pobres na Capitania Geral de Pernambuco (1700-1817). Brasília: Ed. da Universidade de Brasília, 2004, p.315. 
atividades e o processo de recrutamento para essa "classe" de agentes econômicos, todas estas variáveis possuindo ligação direta com as formas de ocupação e transformação das paisagens das hinterlands rurais.

Todas essas questões perpassam uma compreensão mais ampla da formação da sociedade brasileira, que nasceu e se desenvolveu no denso meio florestal. A Mata Atlântica foi o principal baluarte físico-geográfico da formação colonial, fornecendo, ao longo de mais de três séculos, a maior parte da matéria-bruta utilizada no empreendimento ultramarino português na América. 0 desvelamento desse processo de recursalização é tarefa tanto do historiador econômico como do historiador ambiental. Ao primeiro, cabe interrogar-se como a mediatização de um espaço-natureza concreto (a ecologia de floresta tropical) influenciou as dinâmicas produtivas, os circuitos comerciais e os padrões de consumo de uma sociedade atântica pré-industrial, bem como os conflitos sociais engendrados em cada uma dessas esferas. Ao segundo, fica a tarefa de apreender a apropriação do território como um processo informado por racionalidades econômicas diversas e, na maioria das vezes, incongruentes, na medida em que as "oportunidades" oferecidas pela natureza são percebidas diferencialmente ao longo do espectro de atores e grupos sociais, eles mesmos possuidores de "necessidades" discrepantes.

Qualquer que seja o ponto de partida, todavia, o substantivismo econômico impõe-se como abordagem de confluência. Desse modo, a economia pode ser definida como "um processo instituído de interação entre o homem e seu ambiente que leva a uma oferta contínua de meios para a satisfação de necessidades materiais". ${ }^{65} 0$ primeiro termo, processo, designa os movimentos de produção, apropriação e distribuição dos bens materiais, movimentos esses sobre os quais intervêm os componentes ecológicos, tecnológicos e sociais, respectivamente referentes ao ambiente natural, ao equipamento mecânico a ao agrupamento humano. Mas a interação destes elementos não basta para definir uma estrutura dotada de função e história. Donde o segundo termo da definição - a economia como processo instituído - que confere ao primeiro sua unidade, sua estabilidade (interdependência de seus elementos) e sua história (faculdade de se reproduzir).

Não se pode esquecer, todavia, que todo processo, por mais institucionalizado que seja, é sempre permeado pelo conflito social. Neste ponto, torna-se muito cara a noção de costume como a "interface da lei com a prática agrária", tal como desenvolvida por E. P. Thompson e, de modo mais geral, toda a sua concepção de direito comum aplicada ao ambiente, ensejando toda uma análise dos conflitos sociais em torno da apropriação dos recursos silvestres. ${ }^{66} 0$ pano de fundo, aqui, é uma idéia de ambiente

65 POLANYI, Karl. The economy as instituted process. In: POLANYI, Karl; ARENSBERG, Conrad M. \& Harry W. PEARSON. (eds.) Trade and market in the early empires: economies in history and theory. New York: The Free Press, 1957, p.248.

66 THOMPSON, Edward P. Costumes em comum. São Paulo: Cia. das Letras, 1998, p.86-149. 
não somente como materialidade geo-bio-física, mas também como um "campo de batalha", uma arena política onde interesses, ideologias e culturas conflitantes enfrentam-se. Os processos de apropriação do meio florestal são conformados pela ação de indivíduos que buscam, a partir de seus conhecimentos e expectativas histórica e socialmente circunscritos acerca do comportamento do ambiente ecológico e dos demais atores com os quais interagem, aumentar o grau de previsibilidade e controle sobre 0 transcorrer intrinsecamente caótico da vida cotidiana. $E$ isso é feito através da "utilização consciente das incoerências entre os sistemas de normas e de sanções", formulação já clássica de Giovanni Levi. ${ }^{67}$

Enquanto objeto de estudo dessa nova história econômico-ambiental, portanto, a categoria floresta não se apega à tradicional segmentação entre "paisagem natural" e "paisagem cultural". Na floresta, sociedade e natureza imiscuem-se de tal maneira de modo que é impossível distinguir os dois domínios de maneira clara. Longe tanto da imagem do ermo idílico - uma simples "extensão de arvoredos e charnecas que se manteve 'selvagem', onde animais (...) podem correr à vontade" - , quanto da imagem do "jardim domesticado", a floresta apresenta-se com a sua "complexa economia própria": onde se multiplicam os povoamentos, as reivindicações e exigências correntes em relação aos inúmeros recursos ambientais (solo, madeira, frutos, água, etc.) estão submetidas a uma intrincada regulamentação formal e informal. ${ }^{68} \mathrm{~A}$ própria existência da floresta em meio a áreas agricultáveis já constitui, em si, um resultado do direito. ${ }^{69}$

A partir desta concepção de história florestal como história social, podemos estender nossas pesquisas de forma a abarcar o outro lado do fenômeno do desflorestamento, isto é, os processos criativos, de transformação ativa do meio, de produção sócio-cultural e desenvolvimento econômico. Numa obra seminal escrita há mais de oitenta anos - e que, não obstante, os historiadores ambientais relutam em resgatar -, Lucien Febvre resumiu muito bem o espírito dessa história florestal: "É que o homem, pelo mesmo título que a árvore - e ainda melhor, e ainda mais, e de outra forma -, é um dos fatores essenciais da paisagem". ${ }^{70}$ É na apreensão simultânea das diferenças e continuidades entre as agências sociais e naturais, na análise e "descrição densa" dessas articulações que podemos reunir a economia dos homens e a economia da natureza em sistemas compreensivos mais generosos das sociedades e ambientes do passado.

67 LEVI, G iovanni. A herança imaterial: trajetória de um exorcista no Piemonte do século XVII. Rio de J aneiro: Civilização Brasileira, 2000, p.46.

68 THOMPSON, Edward P. Senhores e caçadores. 2a ed. Rio de J aneiro: Paz \& Terra, 1987, p. 32.

69 SILVA, Francisco Carlos T. da. História das paisagens. In: CARDOSO, Ciro F.; VAINFAS, Ronaldo. (ed.) Domínios da história: ensaios de teoria e metodologia. Rio de J aneiro: Elsevier, 1997, p.209.

70 FEBVRE, Lucien. A terra e a evolução humana: introdução geográfica à história. Lisboa: Edições Cosmos, 1991, p.69. (grifo meu). 